\title{
Brain Derived Neurotrophic Factor and Serotonin Levels in Autistic Children: Do They Differ in Obesity?
}

\author{
Ehab R. Abdelraouf ${ }^{1,2}$, Hend Rashad ${ }^{2,3}$, Ayman Kilany ${ }^{1,2}$, Hala M. Zeidan ${ }^{1 *}$, Mohamed Elhadidy ${ }^{1}$, Adel Hashish ${ }^{1}$ D, \\ Neveen Hassan Nashaat ${ }^{1,2}$, Fateheya M. Metwally ${ }^{2,3}$ \\ ${ }^{1}$ Department of Research on Children with Special Needs, Medical Research Division, National Research Centre, Cairo, \\ Egypt; ${ }^{2}$ National Research Centre, Medical Research Centre of Excellence, Cairo, Egypt; ${ }^{3}$ Department of Environmental and \\ Occupational Medicine, Environmental Research Division, National Research Centre, Cairo, Egypt
}

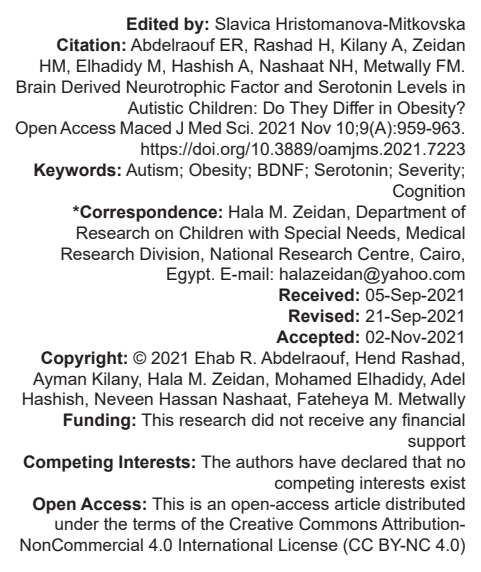

Introduction

The prevalence of obesity in children with autism spectrum disorder (ASD) has been reported to be more than that in general population. It was estimated to range between $17 \%$ and $32 \%$ in ASD children. Individuals with ASD have risk factors which make them more susceptible to weight gain. They manifest feeding disorders such as food selectivity which is commonly for high caloric and low-nutritive kind. Decreased micronutrients intake would lead to high fat deposition in their bodies. Food is also used as reinforcement for autistic children to encourage good behavior [1]. Sedentary lifestyle and some medications such as second generation antipsychotics are also involved in increasing obesity risk. There have been links between obesity and some genetic changes in ASD (e.g., microdeletions of chromosomes 11 and 16) [2]. Furthermore, low socioeconomic status, sleep disorder, hormonal imbalance, gastrointestinal disturbances, and reduced gut microbiota in ASD individuals could play a role in such problem [3].
Changes in the neuroanatomical features of individuals with ASD (either obese or non-obese) have been suggested to be involved in ASD pathogenesis. Children with ASD manifested change in the volume of hypothalamus, amygdala, fornix, hippocampus, and aberrant connections between these areas and other brain areas [4], [5], [6]. Therefore, neurotransmitters responsible for brain functioning in these areas (e.g., brain derived neurotrophic factor [BDNF] and serotonin) were suspected to be altered in the brain and body of such individuals. The levels of BDNF and serotonin (5-HT) have been reported to be altered in ASD. The BDNF was reported to be elevated in ASD children while less than normal in newborns who later develop ASD [7], [8], [9]. The level of blood serotonin was reported to be elevated in 25-60\% of autistic individuals and was linked to familial elevation of 5-HT levels [10], [11]. However, it did not differ in ASD population from normal controls in other studies [12], [13]. It is worth noting that BDNF can cross the blood-brain barrier yet the peripheral serotonin cannot. Thus, brain serotonin could be involved in the pathogenesis of ASD in spite of not differing in its 
level in peripheral blood. On the other hand, peripheral serotonin could be involved in ASD pathogenesis through its role in controlling gut functioning which was reported to be disturbed in ASD [14].

BDNF is essential for connectivity between synapses in brain and peripheral nervous system. It facilitates neuronal growth and supports survival of neurons [15]. It is involved in long-term potentiation which is related to long-term memory. BDNF was reported to be related to serotonergic brain neurons in animal studies [16]. Hypothalamic BDNF was found to be responsible for energy homeostasis and modulation of food intake. Abnormalities of BDNF gene which lead to reduction of BDNF level were associated with hyperphagia and obesity in human and animal models. Besides, administration of BDNF was found to lead to reduction of insulin resistance and induction of weight loss which suggests the role of BDNF as a metabotropic factor [17].

Serotonin serves as a neurotransmitter and an intermediate substrate for melatonin synthesis. It was found to be involved in sensory brain development in animal studies [13]. It regulates behavior and it has a role in appetite suppression, and promotion of energy expenditure which is achieved by facilitating sympathetic drive to brown adipose tissue. The gastrointestinal tract is the main source of peripheral $5-\mathrm{HT}$. Peripheral serotonin has a role in enhancing nutrient absorption and storage. Fatty acids and glucose stimulate the release of serotonin from the duodenum which promotes gut peristalsis and nutrient absorption [18].

In addition to social and behavioral disorders, children with ASD manifest delayed language development. It is the most common presenting symptom for such children. A large percentage of them manifest intellectual disability as well [19]. Obesity was reported to increase the risk of type 2 diabetes, sleep apnea, orthopedic disorders, hypertension, and dyslipidemia [20]. However, the influence of obesity on language and intellectual development and on severity of ASD in autistic children was not adequately investigated. The process of rehabilitation of autistic children is quite challenging and having comorbid obesity increases the health risks and adds more burdens on the family and the health system especially in developing countries. Investigating possible markers of obesity in such children are essential in the process of their management. This will be beneficial to verify the relation or contribution of such markers to obesity and would participate in protecting autistic children from developing obesity and would help in proper management of such children and in reducing health hazards that are related to obesity. Therefore, the aim of this study was to verify the presence of a difference between obese and non-obese autistic children regarding the serum levels of BDNF and serotonin. The influence of obesity on the severity of ASD, the development of intellectual functioning and language abilities was also investigated.

\section{Subjects and Methods}

The study was conducted on 60 ASD children: 30 autistic children with obesity in Group I (6.2 \pm 1.4 ; 26 males and four females) and 30 autistic children without obesity in Group II (age: $5.71 \pm 1.5$; 22 males and eight females). They visited the clinics in the Medical Research Centre of Excellence, National Research Centre, Cairo, Egypt. They were diagnosed to have ASD according to the criteria of DSM-5 [21] and by autism diagnostic interview-revised [22]. Inclusion criteria for participants were having an ASD with a body mass index (BMI) more than $95^{\text {th }}$ percentile for children in Group I and having $\mathrm{BMI}<85^{\text {th }}$ percentile for cases in Group II and having a chronological age range of 3-10 years for both groups. Exclusion criteria were having abnormal general or neurological examination, abnormal motor development, and abnormal facial features suggestive of syndromic involvement, having sleep disorder or MRI abnormalities and being on antipsychotic therapy. The participants were subjected to interviewing for medical history, general examination, otorhinolaryngological examination, and neurological examination. The childhood autism rating scale (CARS) was used for the severity of ASD to be determined [23]. Evaluation to judge the intellectual functioning of the participants was performed by the Arabic version of Stanford Binet Intelligence Scales: Fifth Edition [24], [25]. The Arabic Preschool Language Scale was used for obtaining the language age using the raw scores of the receptive and expressive language abilities in the scale. The scaled scores for receptive and expressive language together with total language performance were used to verify the presence of developmental language delay [26]. Furthermore, $1 \mathrm{~h}$ electroencephalogram (EEG) was performed. Blood samples were obtained from all participants. Serum BDNF concentration was estimated by sandwich ELISA method using the Human BDNF ELISA kit (Sunlong Biotech Co.) [27]. Determination of serotonin serum level was carried out using high-performance liquid chromatography system, Agilent technologies 1100 series, and equipped with a quaternary pump (Quat pump, G131A model) [28]. Written informed consents were obtained from the parents of participants. The study was approved by the Medical research ethics committee of the National Research Centre. Data were analyzed by SPSS computer package with the version 19 windows. When $p<0.05$, the null hypothesis was rejected and results were found to be significant.

\section{Results}

The severity of ASD for participants ranged from mild-moderate to severe degree. CARS scores range 
in Group I was (30-38.5) while in Group II was (3036.5). Children in both groups had intellectual delay or disability. All participants manifested delayed language development as detected by the language scale. There was no significant statistical difference between the groups regarding the CARS scores, IQ level, or language age (Table 1). However, children in Group I had less IQ scores and less language age than those in Group II (IQ range in Groups I and II: 40-68 and 41-72, respectively). The language age for the participants in Group I was less than that in Group II (language age range in Groups I and II: $0.6-3.3$ and $1-4.1$, respectively). None of the participants had EEG changes. The level of BDNF in Group I was less than that in Group II. The level of serotonin in Group I was more than that in Group II. The levels of both markers showed statistically significant difference between groups (Table 1).

Table 1: The difference between autistic cases with obesity and autistic cases without obesity regarding the CARS scores, IQ, language age, BDNF, and serotonin serum levels

\begin{tabular}{llll}
\hline Item & Group I (with obesity) & Group II (without obesity) & p value \\
\hline CARS score & $34.03 \pm 4.3$ & $34.08 \pm 2.1$ & 0.9 \\
IQ & $52.5 \pm 7.2$ & $55.5 \pm 7.9$ & 0.3 \\
Language age (years) & $1.6 \pm 0.9$ & $1.8 \pm 0.7$ & 0.1 \\
BDNF $(\mathrm{pg} / \mathrm{ml})$ & $116.04 \pm 32.1$ & $152.89 \pm 65.3$ & $0.04^{*}$ \\
Serotonin $(\mu \mathrm{g} / \mathrm{ml})$ & $82.9 \pm 39.2$ & $22.6 \pm 4.2$ & $<0.0001^{*}$ \\
\hline CARS: Childhood autism rating scale, IQ: Intelligence quotient, BDNF: Brain derived neurotrophic factor.
\end{tabular}

ARS: Childhood autism rating scale, IQ: Intelligence quotient, BDNF: Brain derived neurotrophic factor.

$P \leq 0.05$ level.

\section{Discussion}

The dysregulation of BDNF and $5-\mathrm{HT}$ signaling has been implicated in the ASD pathogenesis [29], [30]. Furthermore, these neurotransmitters have been involved in metabolic disorders such as obesity. Energy homeostasis is established by food intake which is controlled by hormonal signaling and multiple molecules such as BDNF and 5-HT [31], [32]. In addition to homeostasis, BDNF has a role in memory, learning, and emotional control which are essential for intellectual functioning, behavior, and language development. Therefore, estimating BDNF and 5-HT levels in autistic children with obesity compared to autistic children without obesity could highlight their role in obesity manifested by ASD children. Furthermore, investigating the influence of obesity on severity of ASD, intellectual, and language development is also essential. This would give suggestions about proper obesity management for such children in the future.

BDNF has various roles including neurotrophic activity, inflammation control, and metabolism. It has been hypothesized to be responsible for the tight interaction between brain, the immune system, and the adipose tissue [33]. BDNF is highly expressed in hypothalamus which is responsible for motivation, emotional response, and hormonal balance. Hypothalamus was found to be reduced in volume in ASD individuals. Elevated BDNF in ASD individuals could be a compensation for such reduction [4]. The level of BDNF was found to be significantly reduced in obese autistic children when compared to non-obese autistic children in this study. The IQ and language age of the obese participants were less than those of non-obese ones which could be related to the lower BDNF levels. Episodic memory which is involved in intellectual functioning and language development was reported to depend on brain BDNF [34]. Furthermore, obese children were reported to have altered leptin functioning. Leptin is involved in activation of neurons in hippocampus and limbic system which are related to language and memory development [35]. BDNF acts as a key which regulates weight and food intake. It produces the fullness feeling. Furthermore, it improves cellular insulin sensitivity. It has been proposed as an anti-hyperlipidemic and anti-diabetic treatment [32]. Therefore, its reduction in Group I participants could be involved in their obesity.

It has been reported that low brain serotonin was involved in obesity. Serotonin has a role in controlling satiety and body fat distribution. Moreover, there is a mutual inhibition between $5-\mathrm{HT}$ and dopaminergic systems. The decrease in dopamine mediated reward mechanism leads to increased food intake. On the other hand, high peripheral 5-HT which is mostly derived from gut was found to induce obesity in non-autistic individuals. More cells that are responsible for producing serotonin were detected in the intestine of obese individuals. The gut-derived 5-HT was suggested to be an important driver of human obesity as well as of dysglycemia [31]. Further, high peripheral $5-\mathrm{HT}$ was shown to suppress the adaptive thermogenesis in brown adipose tissue which causes obesity [36]. It is noteworthy that metabolic diseases such as obesity and diabetes (type 2) were associated with decreased thermogenic capacity in brown and beige adipose tissues which could be related to serotonin. Furthermore, peripheral serotonin may have a role in obesity through interaction with leptin.

Leptin is a hormone secreted by adipose tissue which inhibits appetite and regulates body fat and energy. Leptin could also be related to the metabolic role of BDNF. Leptin controls satiety by acting on hypothalamus which is an area where BDNF is highly expressed [37]. High level of leptin excretion due to obesity leads to more fat accrual, hyperglycemia, hyperinsulinemia, and decrease in energy expenditure which all lead to more obesity [38]. Leptin was reported to influence the functioning of hippocampus which suggests its involvement in behavior and memory [39]. BDNF and 5-HT interfere together with other factors to influence the metabolic control of autistic children. The disturbance and changes in their levels may have a potential role in cognitive and language development of autistic children considering their role on brain development which was reported by the previous studies such as Duff and Brown-Schmidt [34] and Meneses and Liy-Salmeron [40]. The influence of obesity on ASD severity, intellectual, and language 
development of ASD children was not distinctive in this study. Nevertheless, further wide scale investigations are needed to verify this issue considering the detected statistically significant changes in the levels of targeted markers in obese autistic children in this study.

\section{Conclusion}

The difference between obese and non-obese autistic children in the levels of BDNF and serotonin could be related to obesity in the participants of this study. The influence of obesity on ASD severity, intellectual, and language development of ASD children was not distinctive in the participants. The influence of such markers on ASD severity and cognitive performance needs further investigations.

\section{Acknowledgment}

We would like to thank our patients and their families.

\section{Compliance with Ethical Standards}

\section{Availability of data and material}

All data are original and available from the corresponding author on reasonable request.

\section{Ethics approval}

"The study was approved by the Medical Research Ethics Committee of the National Research Centre, Egypt."

\section{Consent to participate}

Signed informed consents were taken from the parents of the children after explaining the aim and procedures of the study.

\section{References}

1. Kamal Nor N, Ghozali AH, Ismail J. Prevalence of overweight and obesity among children and adolescents with autism spectrum disorder and associated risk factors. Front Pediatr.
2019;7:38. https://doi.org/10.3389/fped.2019.00038

PMid:30842939

2. Hill AP, Zuckerman KE, Fombonne E. Obesity and autism. Pediatrics. 2015;136(6):1051-61. https://doi:10.1542/ peds.2015-1437

PMid:26527551

3. Dhaliwal KK, Orsso CE, Richard C, Haqq AM, Zwaigenbaum L. Risk factors for unhealthy weight gain and obesity among children with autism spectrum disorder. Int J Mol Sci. 2019;20(13):3285. https://doi.org/10.3390/ijms20133285

PMid:31277383

4. Kurth F, Narr KL, Woods RP, O'Neill J, Alger JR, Caplan R, et al. Diminished gray matter within the hypothalamus in autism disorder: A potential link to hormonal effects? Biol Psychiatry. 2011;70(3):278-82. https://doi.org/10.1016/j. biopsych.2011.03.026

PMid:21531390

5. Saleh M, Nashaat NH, Fahim C, Ibrahim AS, Meguid N MRI surface-based brain morphometry in Egyptian autistic and typically developing children. Folia Phoniatr Logop. 2015;67(1):29-35. https://doi.org/10.1159/000368962 PMid:25967922

6. Cooper RA, Richter FR, Bays PM, Plaisted-Grant KC Baron-Cohen S, Simons JS. Reduced hippocampal functional connectivity during episodic memory retrieval in autism. Cerebral Cortex. 2017;27(2):888-902.

PMid:28057726

7. Kasarpalkar NJ, Kothari ST, Dave UP. Brain-derived neurotrophic factor in children with autism spectrum disorder. Ann Neurosci. 2014;21(4):129-33. https://doi.org/10.5214/ ans.0972.7531.210403 PMid:25452672

8. Meng WD, Sun SJ, Yang J, Chu RX, Tu W, Liu Q. Elevated serum brain-derived neurotrophic factor (BDNF) but not BDNF gene val66met polymorphism is associated with autism spectrum disorders. Mol Neurobiol. 2017;54(2):1167-72. https:// doi.org/10.1007/s12035-016-9721-9

PMid:26820673

9. Skogstrand K, Hagen CM, Borbye-Lorenzen N, Christiansen M, Bybjerg-Grauholm J, Bækvad-Hansen $\mathrm{M}$, et al. Reduced neonatal brain-derived neurotrophic factor is associated with autism spectrum disorders. Transl Psychiatry. 2019;9(1):252. https://doi.org/10.1038/s41398-019-0587-2

10. Gabriele S, Sacco R, Persico AM. Blood serotonin levels in autism spectrum disorder: A systematic review and metaanalysis. Eur Neuropsychopharmacol. 2014;24(6):919-29. https://doi.org/10.1016/j.euroneuro.2014.02.004 PMid:24613076

11. Oteify G, El-Ramly A, Samy A, Soliman E. Evaluation of oxytocin and serotonin levels in autism spectrum disorder. J Med Sci Res. 2018;1(1):66-71. https://doi.org/10.4103/JMISR.JMISR_9_18

12. Spivak B, Golubchik $P$, Mozes $T$, Vered $Y$, Nechmad $A$, Weizman A, et al. Low platelet-poor plasma levels of serotonin in adult autistic patients. Neuropsychobiology. 2004;50(2):157-60. https://doi.org/10.1159/000079108 PMid:15292671

13. Muller CL, Anacker AM, Veenstra-VanderWeele J. The serotonin system in autism spectrum disorder: From biomarker to animal models. Neuroscience. 2017;321:24-41. https://doi. org/10.1016/j.neuroscience.2015.11.010 PMid:26577932

14. Zafeiriou DI, Ververi A, Vargiami E. The serotonergic system: Its role in pathogenesis and early developmental treatment of autism. Curr Neuropharmacol. 2009;7(2):150-7. https://doi. org/10.2174/157015909788848848 


\section{PMid:19949574}

15. Binder DK, Scharfman HE. Brain-derived neurotrophic factor Growth Factors. 2004;22(3):123-31. https://doi.org/10.1080/08 977190410001723308

16. Narita M, Aoki K, Takagi M, Yajima Y, Suzuki T. Implication of brain-derived neurotrophic factor in the release of dopamine and dopamine-related behaviors induced by methamphetamine. Neuroscience. 2003;119(3):767-75. https://doi.org/10.1016/ s0306-4522(03)00099-x

PMid: 12809697

17. Motamedi S, Karimi I, Jafari F. The interrelationship of metabolic syndrome and neurodegenerative diseases with focus on brain-derived neurotrophic factor (BDNF): Kill two birds with one stone. Metabolic Brain Dis. 2017;32(3):651-65. https://doi. org/10.1007/s11011-017-9997-0 PMid:28361262

18. Yabut JM, Crane JD, Green AE, Keating DJ, Khan WI, Steinberg GR. Emerging roles for serotonin in regulating metabolism: New implications for an ancient molecule. Endocrine Rev. 2019;40(4):1092-107. https://doi.org/10.1210/ er.2018-00283

PMid:30901029

19. Meguid NA, Nashaat NH, Hashem HS, Khalil MM. Frequency of risk factors and coexisting abnormalities in a population of Egyptian children with autism spectrum disorder. Asian J Psychiatry. 2018;32:54-8. https://doi.org/10.1016/j. ajp.2017.11.037 PMid:29216607

20. Zheng Z, Zhang L, LiS, Zhao F, Wang Y, Huang L, etal. Association among obesity, overweight and autism spectrum disorder: A systematic review and meta-analysis. Sci Rep. 2017;7:11697. https://doi.org/10.1038/s41598-017-12003-4

21. American Psychiatric Association. Diagnostic and Statistical Manual of Mental Disorders. $5^{\text {th }}$ ed. Arlington, VA: American Psychiatric Association; 2013.

22. Lord C, Rutter M, Le Couteur A. Autism diagnostic interviewrevised: A revised version of a diagnostic interview for caregivers of individuals with possible pervasive developmental disorders. J Autism Dev Disord. 1994;24(5):659-85.

23. Schopler E, Van Bourgondien ME, Wellman GJ, Love SR. Childhood Autism Rating Scale. $2^{\text {nd }}$ ed. Los Angeles, CA: Western Psychological Services; 2010.

24. Roid GH. Stanford-Binet Intelligence Scales: Technical Manual. $5^{\text {th }}$ ed. Itasca, IL: Riverside Publishing; 2003.

25. Farag S. Stanford-Binet Intelligence Test: Standardized Arabic Version. Cairo, Egypt: Anglo Press; 2011.

26. El-Sady SR, El-Shoubary AM, Hafez NG, Abd El-Halim IA, Ewis AA, Abu-Hasseba A. A Standardization, Translation and Modification of the Preschool Language Scale-4, Doctoral Thesis of Phoniatrics. Cairo, Egypt: Faculty of Medicine, Ain Shams University; 2011.

27. da Costa RO, Gadelha-Filho C, da Costa A, Feitosa ML, de Araújo DP, de Lucena JD, et al. The treadmill exercise protects against dopaminergic neuron loss and brain oxidative stress in parkinsonian rats. Oxid Med Cell Longev. 2017;2017:2138169. https://doi.org/10.1155/2017/2138169 PMid:28713483

28. Hussein J, El-Matty DA, El-Khayat Z, Abdel-Latif Y. Brain neurotransmitters in diabetic rats treated with coenzyme Q10. Int J Pharm Pharm Sci. 2012;4(4):554-6.

29. Nakamura K, Sekine Y, Ouchi Y, Tsujii M, Yoshikawa E, Futatsubashi M, et al. Brain serotonin and dopamine transporter bindings in adults with high-functioning autism. Arch General Psychiatry. 2010;67(1):59-68. https://doi.org/10.1001/ archgenpsychiatry.2009.137

PMid:20048223

30. Saghazadeh A, Rezaei N. Brain-derived neurotrophic factor levels in autism: A systematic review and meta-analysis. J Autism Dev Disord. 2017;47(4):1018-29. https://doi.org/ doi:10.1007/s10803-016-3024-x

PMid:28138831

31. Kesić M, Baković P, Horvatiček M, ProustB, Štefulj J, Čičin-Šain L. Constitutionally high serotonin tone favors obesity: Study on rat sublines with altered serotonin homeostasis. Front Neurosci. 2020;14:219. https://doi.org/10.3389/fnins.2020.00219 PMid:32269507

32. Pandit M, Behl T, Sachdeva M, Arora S. Role of brain derived neurotropic factor in obesity. Obesity Med. 2020;17:100189. https://doi.org/10.1016/j.obmed.2020.100189

33. Sandrini L, Di Minno A, Amadio P, leraci A, Tremoli E, Barbieri SS. Association between obesity and circulating brainderived neurotrophic factor (BDNF) levels: Systematic review of literature and meta-analysis. Int J Mol Sci. 2018;19(8):2281. https://doi.org/10.3390/ijms19082281

PMid:30081509

34. Duff MC, Brown-Schmidt S. The hippocampus and the flexible use and processing of language. Front Hum Neurosci. 2012;6:69. https://doi.org/10.3389/fnhum.2012.00069 PMid:22493573

35. Zou X, Zhong L, Zhu C, Zhao H, Zhao F, Cui R, et al. Role of leptin in mood disorder and neurodegenerative disease. Front Neurosci. 2019;13:378. https://doi.org/10.3389/fnins.2019.00378 PMid:31130833

36. Kelleni MT. Role of central and peripheral serotonin in obesity: What to expect in the near pharmacotherapy future? Adv Obesity Weight Manage Control. 2018;8(6):291. https://doi. org/10.15406/aowmc.2018.08.00261

37. Shedlock K, Susi A, Gorman G, Hisle-Gorman E, ErdieLalena CR, Nylund CM. Autism spectrum disorders and metabolic complications of obesity. J Pediatr. 2016;178:183-7. https://doi.org/10.1016/j.jpeds.2016.07.055 PMid:27592097

38. Soliman AT, Yasin M, Kassem A. Leptin in pediatrics: A hormone from adipocyte that wheels several functions in children Indian J Endocrinol Metab. 2012;16(3):S577-87. https://doi. org/10.4103/2230-8210.105575 PMid:23565493

39. Farr SA, Banks WA, Morley JE. Effects of leptin on memory processing. Peptides. 2006;27(6):1420-5. https://doi. org/10.1016/j.peptides.2005.10.006 PMid: 16293343

40. Meneses A, Liy-Salmeron G. Serotonin and emotion, learning and memory. Rev Neurosci. 2012;23(5-6):543-53. https://doi. org/10.1515/revneuro-2012-006

PMid:23104855 